\section{Gastrointestinal manifestations of common variable immunodeficiency disease}

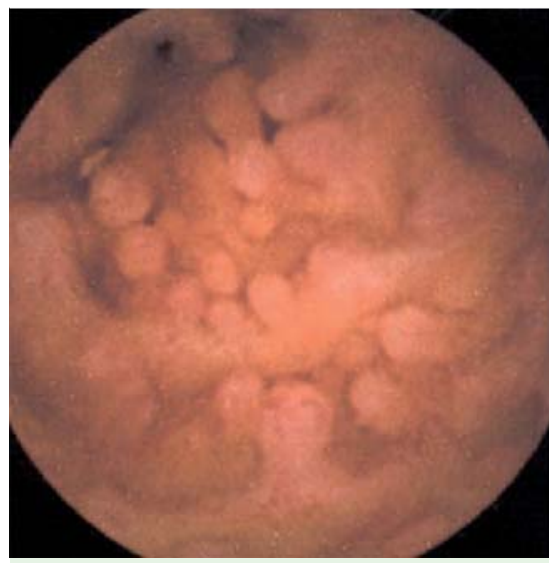

Fig. 1 Capsule endoscopy image showing the small bowel of a 30-year-old woman with common variable immunodeficiency disease (CVID) and a 2-week history of diarrhea and weight loss.
A 30-year-old woman with history of common variable immunodeficiency disease (CVID), Von Willebrand disease, and factor VII hemophilia presented to the emergency department with complaints of diarrhea and weight loss for 2 weeks. On admission her vital signs were stable. She reported 6-8 watery bowel movements per day, which were not improved with Imodium, but had no hematochezia or melanotic stools. The findings from the physical examination were noncontributory. She had work-up for diarrhea, which was negative for infectious etiology. A positive fecal fat test suggested malabsorption.

Of note, she had undergone a colonoscopy in 2010, which had been indicated for chronic diarrhea, and biopsy results had revealed nodularity in the ascending colon and rectal mucosa consistent with lymphoid hyperplasia.

She also underwent esophagogastroduodenoscopy during her present admission in 2014, which revealed no irregularities, and a biopsy, which was negative for celiac sprue. Subsequently, she underwent capsule endoscopy ( $\mathbf{F i g} \mathbf{1}$ ) and small-bowel enteroscopy ( $\bullet$ Fig. 2), which revealed grossly nodular lymphoid hyperplasia throughout the distal small bowel. Small-bowel enteroscopy revealed areas with multiple 4-7-mm sessile polyps and no bleeding in the proximal and distal jejunum ( Fig.2). The patient responded well to budesonide and metronidazole and underwent follow-up with a gastrointestinal (GI) specialist.

CVID is a primary immunodeficiency disorder that is characterized by impaired B-cell differentiation and defective immunoglobulin production [1]. GI manifestations of CVID include diarrhea, malabsorption, weight loss, acute infections, and inflammatory bowel disease. Diffuse
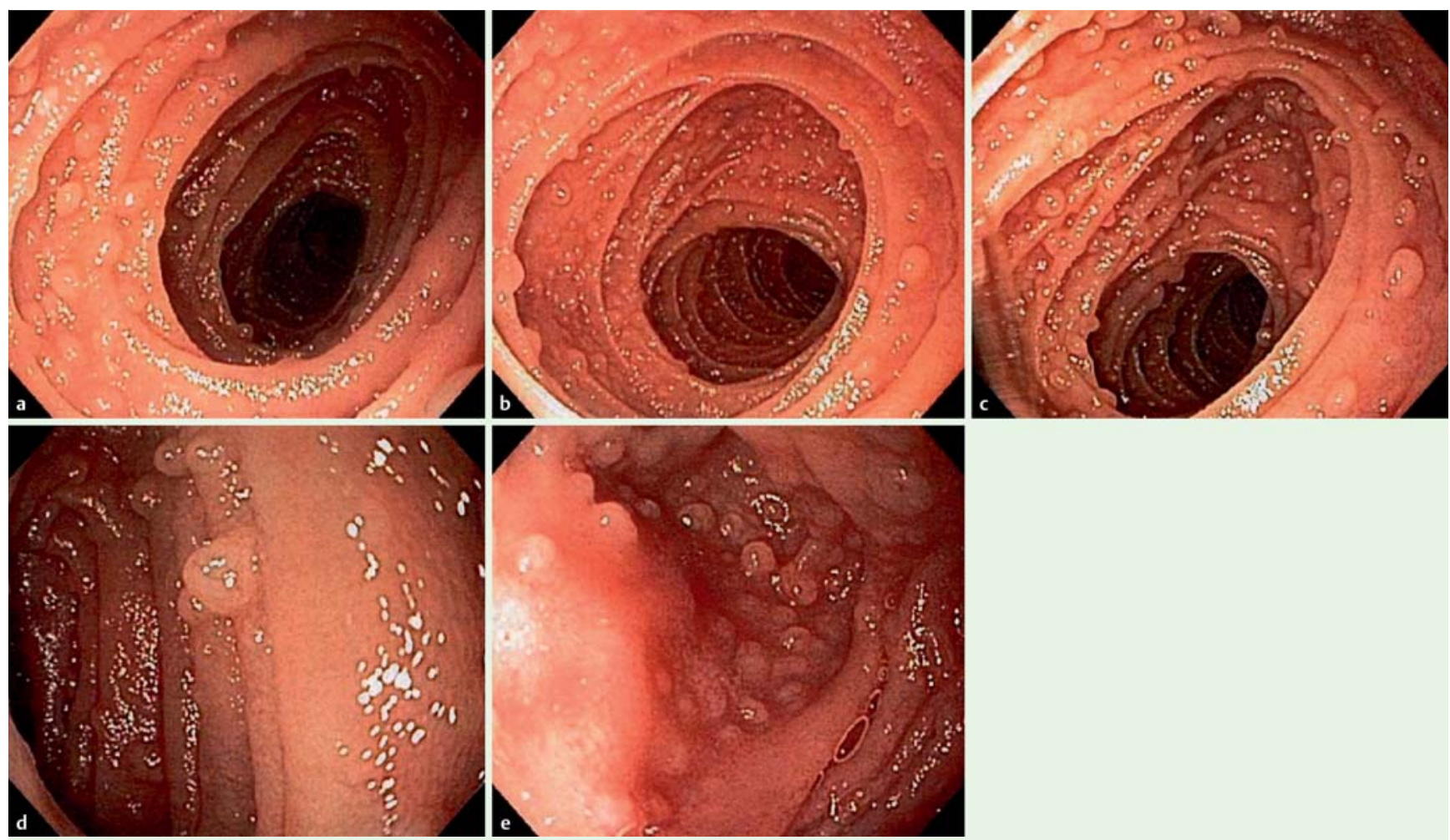

Fig. 2 Small-bowel enteroscopy appearance of diffuse nodular lymphoid hyperplasia in a 30-year-old woman with common variable immunodeficiency disease (CVID), who presented with diarrhea and weight loss for 2 weeks: a, b jejunum, $50-60 \mathrm{~cm}$ from the pylorus; c jejunum $60-70 \mathrm{~cm}$ from the pylorus; d, e duodenum $30-40 \mathrm{~cm}$ from the pylorus. 
nodular lymphoid hyperplasia is a rare lymphoproliferative disorder of the GI tract with uncertain etiology [2,3]. It is believed that exposure to infectious agents leads to the repetitive stimulation of lymphoid follicles and eventual hyperplasia $[4,5]$.

Endoscopy_UCTN_Code_CCL_1AC_2AH

\section{Competing interests: None}

\section{Joshua Samuel', Nicholas Agresti², Juan Munoz ${ }^{2}$}

${ }^{1}$ UF Health Jacksonville Department of Internal Medicine

2 UF Health Jacksonville Gastroenterology

\section{References}

1 Conley ME, Notarangelo LD, Etzioni A. Diagnostic criteria for primary immunodeficiencies. Clin Immunol 1999; 93: 190 - 197

2 Khuroo MS, Khuroo NS, Khuroo MS. Diffuse duodenal nodular lymphoid hyperplasia: a large cohort of patients etiologically related to Helicobacter pylori infection. BMC Gastroenterol 2011; 11: 36

3 Luzi G, Zullo A, Iebba F et al. Duodenal pathology and clinical-immunological implications in common variable immunodeficiency patients. Am J Gastroenterol 2003; 98: 118-121

4 Cunningham-Rundles C, Siegal FP, Cunningham-Rundles $S$ et al. Incidence of cancer in 98 patients with common varied immunodeficiency. J Clin Immunol 1987; 7: $294-$ 299

5 Webster ADB. Immunodeficiency and gastrointestinal disease. In: Triger DR, ed. Clinical immunology of the liver and gastrointestinal tract. Bristol: John Wright; 1986: 127-49
Bibliography

Dol http://dx.doi.org/

10.1055/s-0034-1392088

Endoscopy 2015; 47: E183-E184

(c) Georg Thieme Verlag KG

Stuttgart · New York

ISSN 0013-726X

Corresponding author

Joshua Samuel, MD

UF College of Medicine Jacksonville

653-1 West 8th Street

L18, Jacksonville

FL 32209

USA

Fax: +1-904-244-7388

Joshua.Samuel@jax.ufl.edu 